\title{
NEW METHODS FOR MEASURING PERFORMANCE OF MONOLITHIC MULTI-JUNCTION SOLAR CELLS
}

\author{
D. L. King, B. R. Hansen, J. M. Moore, and D. J. Aiken \\ Sandia National Laboratories, Albuquerque, NM, 87185
}

\begin{abstract}
The commercialization of multi-junction solar cells for both space and terrestrial applications has increased the need to accurately determine cell performance using typical solar simulators and test equipment. This paper describes specific test methods recently applied in characterizing the performance of both tandem and triplejunction solar cells. Methods applied included: currentvoltage measurements in forward and reverse bias using a xenon-arc solar simulator, absolute spectral response measurements of separate junctions using both light and voltage bias, a device simulation model, and a spectral mismatch calculation procedure tailored to multi-junction cells. Procedures are illustrated using measurements for GalnP/GaAs tandem cells, GalnP/GaAs/Ge triple-junction cells, and Ge cells supplied by different manufacturers.
\end{abstract}

\section{INTRODUCTION}

The high performance potential of multi-junction solar cells has been recognized for over 30 years [1]. Today, the reality is that several U.S. manufacturers have highly efficient multi-junction solar cells in production, primarily for space power applications [2,3]. These high efficiency devices are also being seriously considered for terrestrial applications as well $[4,5]$. Unfortunately, along with the high performance has come device complexity. This device complexity is not as evident in the actual application of the multi-junction cells as it is when conducting detailed performance testing in the laboratory. The complexity stems primarily from the cells having only two "terminals," meaning the separate junctions cannot be tested independently. Nonetheless, detailed performance testing can't be avoided; it is required both for optimizing cell manufacturing procedures and for modeling the performance of systems using the cell technology. Other researchers have also documented their efforts to characterize multi-junction solar cells $[6,7,8]$, and a standardized test procedure is currently under development [9]. The purpose of this paper is to illustrate and document new test procedures we've found effective in characterizing the performance of recently manufactured multi-junction cells.

\section{SIMULATION OF MULTI-JUNCTION CELLS}

Numerical simulation (modeling) of a multi-junction cell helps clarify the interactive influences of the currentvoltage (I-V) characteristics of individual junctions on the
I-V curve for the composite cell. A simulation code called PVSIM was used to interpret the behavior of monolithic, two-terminal, multi-junction cells [10]. PVSIM uses a twodiode equivalent circuit with shunt and series resistance components to simulate the behavior of each junction. The model also includes parameters to simulate the reverse-voltage ( $2^{\text {nd }}$ quadrant) "breakdown" of each junction. Figure 1 illustrates both the simulation and the measured I-V characteristics of a triple-junction GalnP/GaAs/Ge solar cell for a one-sun AM1.5 standard solar spectrum. The "composite" I-V curve in the figure is simply the summation of the voltage produced by each junction at a given current level. For this case, the solar simulator provided a spectrum that closely matched the standard spectrum, so the short-circuit current $\left(I_{\mathrm{sc}}\right)$ values for the separate junctions mimic the situation for the standard reporting condition. The reverse breakdown voltages for all three junctions were determined from other tests. The top GalnP junction limited the $I_{s c}$ of the multijunction cell, and the reverse voltage characteristics of the other two junctions did not influence the shape of the composite $1-V$ curve in the $1^{\text {st }}$ quadrant.

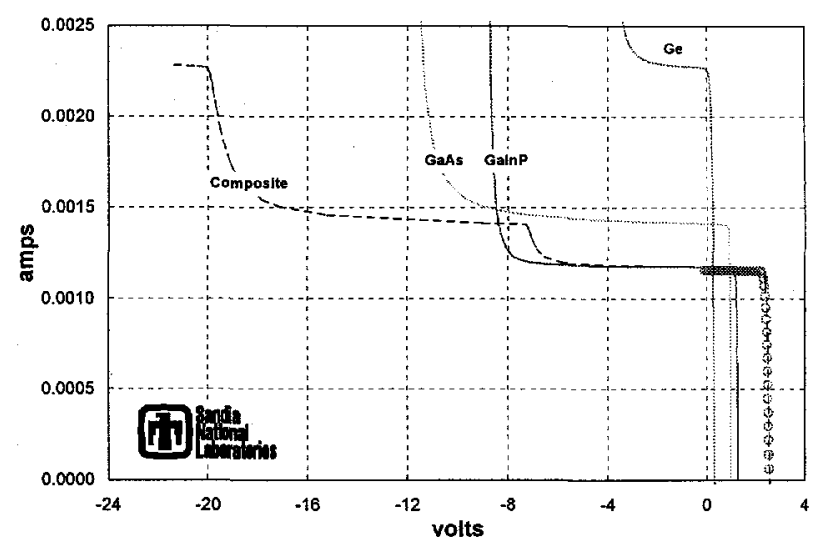

Fig. 1. Measured (symbols) and simulated one-sun $\mathrm{I}-\mathrm{V}$ for triple-junction cell under ASTM AM1.5 standard spectrum.

Figure 2 illustrates a situation where the solar simulator didn't match the ASTM standard solar spectrum and had inadequate long-wavelength light for the bottom Ge junction. In this case, the Ge junction limited the $I_{s c}$ of the cell and its reverse voltage characteristics dramatically altered the shape of the composite I-V curve. Without a simulation model or an understanding of the reverse-voltage characteristics of each junction, it is 


\section{DISCLAIMER}

This report was prepared as an account of work sponsored by an agency of the United States Government. Neither the United States Government nor any agency thereof, nor any of their employees, make any warranty, express or implied, or assumes any legal liability or responsibility for the accuracy, completeness, or usefulness of any information, apparatus, product, or process disclosed, or represents that its use would not infringe privately owned rights. Reference herein to any specific commercial product, process, or service by trade name, trademark, manufacturer, or otherwise does not necessarily constitute or imply its endorsement, recommendation, or favoring by the United States Government or any agency thereof. The views and opinions of authors expressed herein do not necessarily state or reflect those of the United States Government or any agency thereof. 


\section{DISCLAIMER}

Portions of this document may be illegible in electronic image products. Images are produced from the best available original document. 
difficult to determine performance at standard reporting conditions starting with a measured I-V curve as shown in Figure 2.

This situation may also be of practical importance for concentrator modules developed to use high performance GainP/GaAs/Ge cells. The optical material (acrylic) used for concentrating Fresnel lenses has relatively low transmittance at wavelengths greater than $1200 \mathrm{~nm}$, which will significantly reduce the $\mathrm{I}_{\mathrm{sc}}$ of the $\mathrm{Ge}$ junction, however, probably not to the extent illustrated in Figure 2. In addition, as documented elsewhere, special attention will need to be paid to the refractive characteristics of the facets on Fresnel lenses [11]. Otherwise, multi-junction cell performance may be significantly limited by chromatic aberration in the lens which could produce a highly nonuniform distribution of the influential wavelengths of light for each separate junction. Non-uniform illumination of the separate junctions results in performance losses due to the emitter sheet resistance.

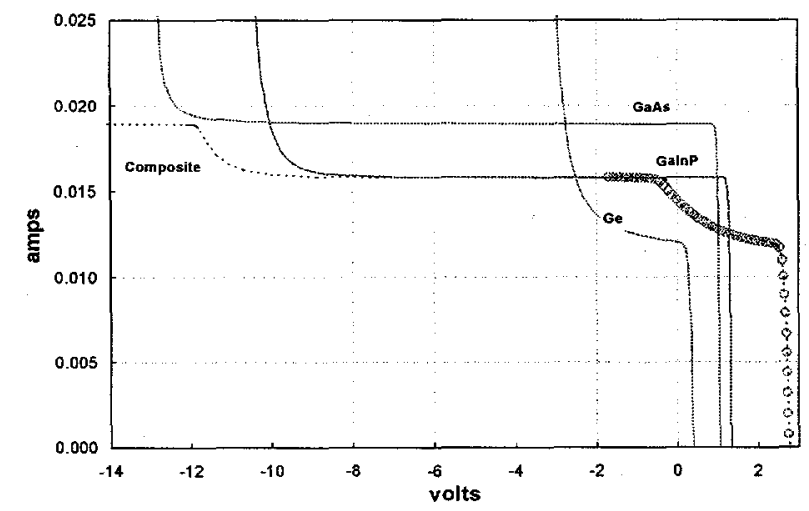

Fig. 2. Measured (symbols) and simulated I-V curve at $12 \mathrm{X}$ concentration using solar simulator with inadequate long-wavelength light for $\mathrm{Ge}$ junction.

\section{SPECTRAL RESPONSE MEASUREMENTS}

In order to properly determine the performance of a multi-junction cell at standard reporting conditions, a method for determining the relative short-circuit currents of the separate junctions is required. The most commonly used approach is to measure spectral response. Spectral response is typically defined as the current density $\left(A / \mathrm{cm}^{2}\right)$ produced per monochromatic power $\left(\mathrm{W} / \mathrm{cm}^{2}\right)$ incident on the cell at a voltage bias of zero volts (short circuit). Achieving this specific condition for the separate junctions in a multi-junction cell can be difficult. Spectral response measurements must provide either "absolute" spectral response or a direct relative comparison between the separate junctions. Numerically convolving the desired (standard) solar spectrum with the spectral response measurements provides relative short-circuit current densities $\left(\mathrm{J}_{\mathrm{sc}}\right)$ for the separate junctions. Figure 3 illustrates successful measurement of the absolute spectral response for the separate junctions in a GalnP/GaAs/Ge triple-junction cell. The irregular response of the $\mathrm{Ge}$ junction was the result of optical interference in the very thin GalnP and GaAs epitaxial layers. Absolute spectral response measurements, when coupled with spectral reflectance measurements, also provides a means for calculating the internal quantum efficiency (IQE) for each junction. IQE provides valuable information for optimization of manufacturing procedures.

\section{Measurement Equipment}

The spectral response measurement equipment at Sandia uses an Oriel quartz-tungsten-halogen light source, a Digichrom Model 240 monochromator, a lightbeam chopper, a Stanford Research lock-in amplifier, and a Stanford Research preamplifier, to provide cell response over a spot-size of about $16 \mathrm{~mm}^{2}$. Reference detectors calibrated by the National Institute of Standards and Technology (NIST) provide absolute calibration of the monochromatic beam of light. Cells are mounted on a temperature-controlled vacuum fixture during testing. For the cells described in this paper, we used a combination of Oriel optical filters (band-pass and long-pass), and variable intensity lasers to "light bias" the separate junctions. A 532-nm diode-laser was used to bias the GalnP junction, an 832-nm diode-laser the GaAs junction, and a 1064-nm $\mathrm{YaG}$ laser the $\mathrm{Ge}$ junction. The wavelength range for the light biases must be tailored to the bandgap and spectral response characteristics of the separate junctions in a multi-junction cell. In general, optical filters with desired transmittance characteristics over a wide wavelength range (300 to $1800 \mathrm{~nm}$ ) can be difficult to find. We've found that variable intensity lasers often provide the best alternative for light biasing.

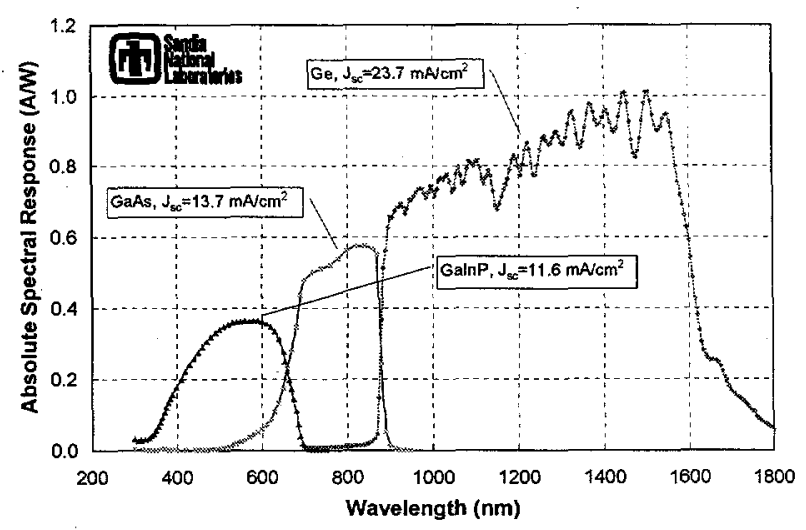

Fig. 3. Absolute spectral response of separate junctions in a high-performance two-terminal GalnP/GaAs/Ge triplejunction solar cell.

\section{Measurement Procedure}

For series-connected junctions that are illuminated by the standard solar spectrum, the junction with the lowest $I_{s c}$ is typically assumed to limit the short-circuit current of the composite cell to a value equivalent to its own shortcircuit current. However, this assumption is only valid for ideal situations where individual junctions don't have shunt-resistance or reverse-breakdown characteristics that alter the shape of the composite I-V curve in the $1^{\text {st }}$ quadrant $(V \geq 0)$. Figure 4 illustrates a measured I-V curves for an individual $1-\mathrm{cm}^{2} \mathrm{Ge}$ cell, and also the

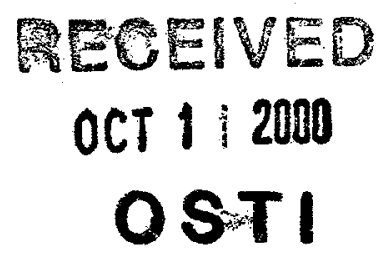


measured "composite" I-V curve with the $\mathrm{Ge}$ cell electrically interconnected in series with a $4-\mathrm{cm}^{2}$ GalnP/GaAs tandem -junction cell. For this special case, the $I_{\text {sc }}$ of the $\mathrm{Ge}$ cell was lower than the tandem-junction cell because of its smaller area. The measured curves illustrate how the reverse breakdown of the $\mathrm{Ge}$ cell dramatically influenced the shape of the composite I-V curve in a manner similar to that previously shown in Figure 2. The reverse breakdown voltage for a variety of Ge junctions was found to be in the range from -1 to $-5 \mathrm{~V}$. The implication of this discussion for spectral response measurements is that a combination of light- and voltagebias must be found that provides an appropriate "shortcircuit condition" for the junction of interest. For the series-connected situation in Figure 4, a forward bias of 2.2 volts would be required to establish an appropriate situation for measuring the spectral response of the $\mathrm{Ge}$ junction.

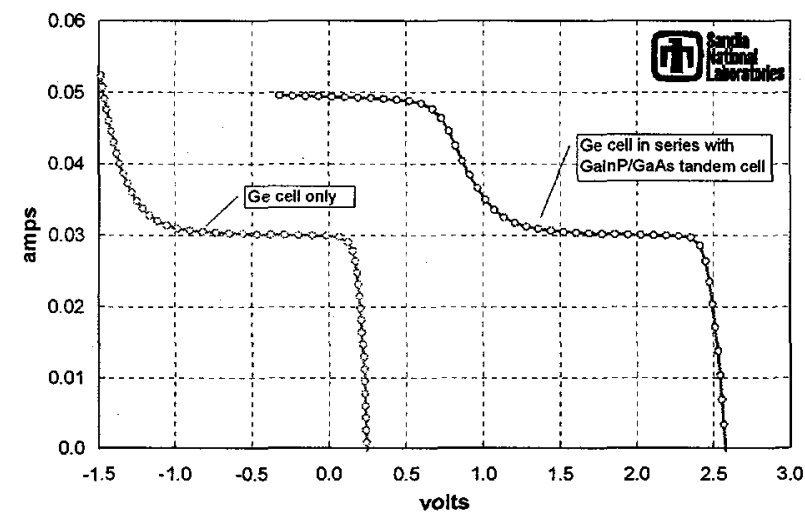

Fig. 4. Measured I-V curve for an individual $\mathrm{Ge}$ cell and for the composite I-V curve with the Ge cell in series with a GalnP/GaAs tandem cell.

Figure 5 illustrates a simulated condition for the separate junctions in a triple-junction cell. This simulation represents a situation where the top two junctions (GalnP and $\mathrm{GaAs}$ ) were light biased with continuous (dc) laser illumination and a pulsed (chopped) monochromatic illumination was used to measure the spectral response of the bottom $\mathrm{Ge}$ junction. The lock-in amplifier associated with the measurement system separates the response due to the chopped monochromatic light from the steady laser illumination used as a light bias. The "composite" curve in the figure represents the steady or "dc" response from the two-terminal triple junction cell, as a function of voltage and as if the pulsed monochromatic light was on continuously. It can be seen from the figure that in order to reach a point on the composite I-V curve representative of the short-circuit condition for the $\mathrm{Ge}$ junction a forward voltage bias of about $2.2 \mathrm{~V}$ is required. Another unfortunate observation from these simulations is that a near infinite number of combinations of light bias, voltage bias, and monochromatic wavelength are possible, thus complicating the measurement process. However, a procedure has been found that makes the measurement process manageable. This process involves minimizing unwanted contributions to spectral response from the junctions not being characterized.
For instance, when measuring spectral response for the $\mathrm{Ge}$ junction, there should be no response at $550-\mathrm{nm}$ since that wavelength is absorbed by the top GalnP junction. However, if there is response at $550 \mathrm{~nm}$, a situation similar to Figure 5 exists. At $550-\mathrm{nm}$, no current is being generated in the $\mathrm{Ge}$ junction so its $\mathrm{I}-\mathrm{V}$ curve would be shifted down to $I_{s c}=0$ which results in the composite I-V curve also shifting down and to the left. Note that this shifting results in a situation at $V=0$ where the top GalnP junction was contributing current to the spectral response measurement at $550 \mathrm{~nm}$ erroneously suggesting that the $\mathrm{Ge}$ junction was responding at that wavelength. This situation can be corrected by adding a forward voltage bias across the multi-junction cell. Increasing the voltage bias will minimize any unwanted contribution from the GalnP junction. A similar argument can be made concerning unwanted contribution from the GaAs junction at a wavelength of $800 \mathrm{~nm}$.

Thus, a reasonably straight forward procedure to use when measuring the spectral response of the $\mathrm{Ge}$ junction is to apply light bias to the GalnP and GaAs junctions and then increase the voltage bias to minimize the measured spectral response at $550 \mathrm{~nm}$ and at $800 \mathrm{~nm}$. Minimizing the unwanted contributions from the GalnP and GaAs junctions tends to maximize the response from the $\mathrm{Ge}$ junction and provides the "correct" spectral response. The simulation in Figure 5 also suggests that voltage bias would not be necessary to measure the spectral response of the $\mathrm{Ge}$ junction if its reverse breakdown voltage was significantly larger in magnitude than the composite voltage of the multi-junction cell.

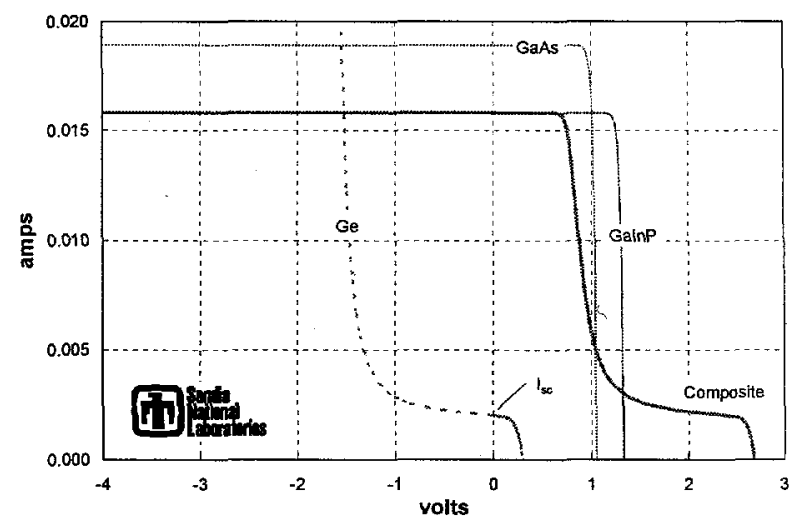

Fig. 5. Simulated I-V characteristics for spectral response measurement of the $\mathrm{Ge}$ junction in a triple-junction cell at a wavelength of perhaps 1000-nm. GalnP and GaAs junctions are continuously light-biased and a pulsed (chopped) monochromatic beam used to illuminate $\mathrm{Ge}$.

\section{Validation of Procedure}

In order to better understand the combination of voltage and light-bias levels required for spectral response measurements, the same experimental (two component) multi-junction cell measured in Figure 4 was used. The $\mathrm{Ge}$ cell in this case had electrically inactive "window" layers of GalnP and GaAs epitaxially deposited on its top surface, thus mimicking the optical characteristics in a monolithic GalnP/GaAs/Ge device. 
For this unique situation, the spectral response of the $\mathrm{Ge}$ cell could be independently measured, and its spectral response could also be measured when electrically connected in series with the GalnP/GaAs tandem cell. Validation of our spectral response measurement procedure for multi-junction cells, with both light and voltage bias, was achieved when spectral response measurements for the series-connected Ge cell matched those obtained for the Ge cell by itself. Figure 6 shows spectral response measurements for the Ge junction in the experimental device for different combinations of lightbias on the top two junctions and voltage-bias across all three junctions. When the appropriate combination of light-bias and voltage-bias were achieved, the unwanted current generation at 550 and $800 \mathrm{~nm}$ was minimized, and the correct result for the $\mathrm{Ge}$ junction was achieved.

\section{SOLAR SIMULATOR SPECTRUM VERSUS DESIRED STANDARD SPECTRUM}

The spectral irradiance provided by solar simulators never exactly matches the solar spectral distributions established as standards for different air mass conditions (AM1.5 or AM0), particularly for multi-junction cells where spectral response may span the wavelength range from 300 to $1800 \mathrm{~nm}$. A few multiple-light-source simulators have been developed to minimize this problem but they are complex and expensive. In any case, when using simulators to measure the performance of multi-junction cells, it is necessary to apply multiple spectral mismatch corrections [12]. However, simply calculating the spectral mismatch correction for the junction limiting the $I_{s c}$ during measurement and then applying that correction to the measured I-V curve is not a valid approach. Figure 2 illustrates an extreme example. A calculated spectral correction for the Ge junction would suggest that the measured $\mathrm{I}-\mathrm{V}$ curve needs to almost double in current for the standard spectrum, clearly unrealistic because the top (GalnP) junction would limit the multi-junction cell's $I_{s c}$ after the Ge junction increased by about $10 \%$ in current.

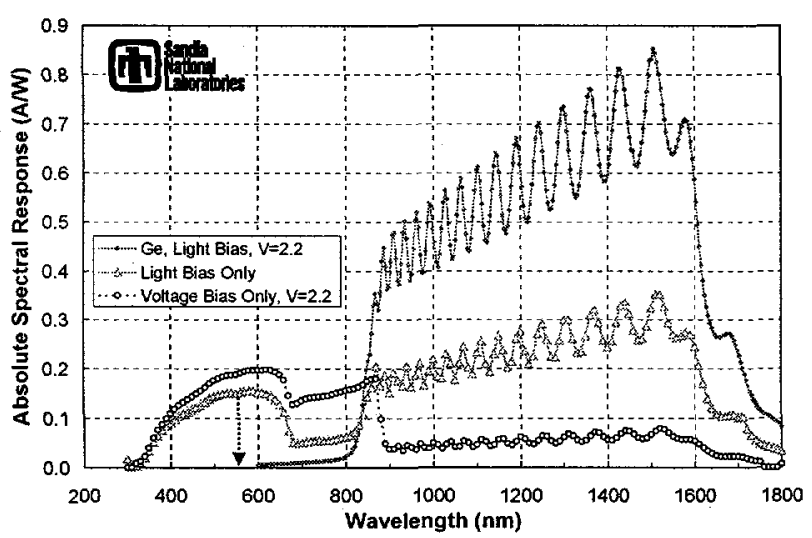

Fig. 6. Measurements illustrating the influence of light and voltage bias on the response measured for the bottom $\mathrm{Ge}$ junction in a GalnP/GaAs/Ge cell.

A more valid approach for multi-junction cells is to calculate mismatch corrections for each junction, $\mathrm{M}_{\mathrm{i}}$, and calculate $J_{s c}$ ratios relative to the junction limiting the $I_{s c}$ during I-V measurements. Ideally, the simulator spectrum can be altered such that the same junction limits $I_{s c}$ for both the simulator and the standard solar spectrum. The $J_{s c}$ ratios are calculated using a numerical integration of the absolute spectral response measurements and the measured spectral irradiance of the solar simulator. This procedure is expressed by Equations 1 through 5, and provides the corrected short-circuit current, $I_{\text {sco, }}$, for the multi-junction cell at standard reporting conditions (SRC).

$$
\begin{aligned}
& I_{s c m}=I_{s c 1} \quad \text { (Measured } I_{s c} \text { for limiting junction.) } \\
& I_{s c o 1}=\frac{I_{s c 1}}{M_{1}} \quad \text { (Limiting junction at SRC.) } \\
& I_{s c o 2}=\frac{J_{s c 2}}{J_{s c 1}} \cdot \frac{I_{s c 1}}{M_{2}} \quad \text { (Second junction at SRC.) } \\
& I_{s c o 3}=\frac{J_{s c 3}}{J_{s c 1}} \cdot \frac{I_{s c 1}}{M_{3}} \quad \text { (Third junction at SRC.) } \\
& I_{s c o}=M I N\left[I_{s c o 1}, I_{s c o 2}, I_{s c o 3}\right] \quad \text { (Device } I_{s c} \text { at SRC) }
\end{aligned}
$$

\section{REVERSE VOLTAGE MEASUREMENTS}

There is an alternative to complex spectral response measurements for determining relative short-circuit currents for the separate junctions in a multi-junction cell. However, the potential for cell damage is involved! When illuminated by a light source simulating the standard solar spectrum, reverse voltage I-V measurements for multijunction cells can provide valuable insight for interpreting both performance and spectral response measurements. For negative voltages $\left(2^{\text {nd }}\right.$ quadrant), junction shunt resistance and junction breakdown characteristics dictate the shape of the I-V curve. As an example, Figure 7 illustrates measurement of the reverse voltage characteristics for a GalnP/GaAs/Ge triple-junction cell. Note that this measured behavior closely mimics the simulation for the composite I-V curve previously shown in Figure 1. The relative short-circuit currents for the three separate junctions are directly indicated by the three "plateaus" observed. The inflections in the curve indicate the onset of reverse breakdown in the junctions indicated. $I_{s c}$ ratios relative to the GalnP junction can be calculated for the other two junctions by using the $I_{s c}$ measured for the GalnP as the divisor. These Isc ratios can be used for two purposes. They can be used to scale spectral response measurements for separate junctions if the spectral response measurement procedure does not provide absolute values directly. The $I_{\mathrm{sc}}$ ratios can also be used instead of $J_{s c}$ ratios in Equations 3 and 4 to determine the appropriate spectral mismatch correction.

\section{CONCLUSIONS}

Test procedures have been demonstrated that should assist manufacturers in the development of multi-junction solar cells, and also contribute to the development of standardized test procedures for these devices. 


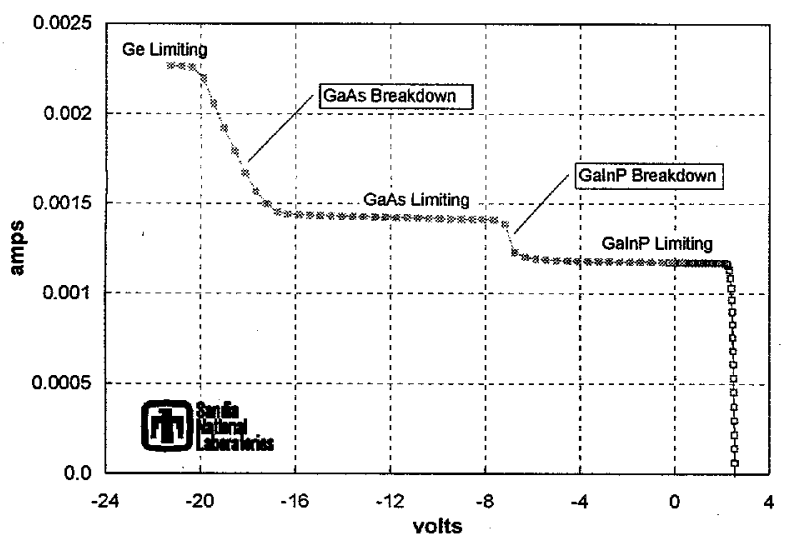

Fig. 7. Reverse-voltage one-sun I-V measurement for GalnP/GaAs/Ge triple-junction cell showing breakdown and current-limiting plateaus for separate junctions.

\section{AKNOWLEDGEMENTS}

The authors applaud recent advances in multi-junction cell technology and acknowledge collaborative interactions with the cell manufacturers that provided cells for our experimental investigations. Valuable discussions with Keith Emery and Dan Friedman at NREL are also acknowledged. [Sandia is a multiprogram laboratory operated by Sandia Corporation, a Lockheed Martin Company, for the U.S. Department of Energy under contract DE-AC04-94AL85000.]

\section{REFERENCES}

[1] E. D. Jackson, Transaction of Conference on use of Solar Energy, Tucson 1955, U. of Arizona Press, 5, 1958, pp.122-125.

[2] P. Pien, et al., "Triple-Junction GalnP/GaAs/Ge Solar Cells - Production Status," this conference.

[3] H. Q. Hou, et al., "Very-High-Efficiency InGaP/GaAs Dual-Junction Solar Cell Manufacturing at EMCORE Photovoltaics," this conference.

[4] H. L. Cotal, et al., 32.3\%-Efficient Triple-Junction solar Cells: Promise and Challenges for Application in HighConcentration-Ratio PV Systems, "this conference.

[5] M. O'Neill, "Development of Terrestrial Concentrator Modules Incorporating High-Efficiency Multi-Junction Cells," this conference.

[6] J. Burdick and T. Glatfelter, "Spectral Response and I$\checkmark$ Measurements of Tandem a-Si Solar Cells," Solar Cells 18, 1986, pp.301-314.

[7] K. Heidler, et al., "Progress in Measurement of MultiJunction Devices at ISE," $22^{\text {nd }}$ IEEE PVSC, pp. 430-435.

[8] K. Emery, et al., "Procedures for Evaluating Multijunction Concentrators," this conference.

[9] ASTM E44 Draft 200R9, "Standard Test Method for "Measurement of Electrical Performance and Spectral Response of Multijunction PV Cells and Modules.

[10] D. King, et al., "PVSIM: A Simulation Program for Photovoltaic Cells, Modules, and Arrays," $25^{\text {th }}$ IEEE PVSC, pp.1295-1297.

[11] L. W. James, "Effects of Concentrator Chromatic Aberration on Multi-Junction Cells," $1^{\text {st }}$ WCPEC, 1994, pp.1799-1802.
[12] ASTM E 973, Standard Test Method for Determination of the Spectral Mismatch Parameter between a Photovoltaic Device and a Photovoltaic Reference Cell. 